\title{
Matching actual treatment with patient administration-route-preference improves analgesic response among acute low back pain patients - a randomized prospective trial
}

\author{
Adi Shani ${ }^{1}$, Michal Granot ${ }^{2}$, Gleb Mochalov ${ }^{3}$, Bennidor Raviv ${ }^{4,5}$ and Nimrod Rahamimov ${ }^{4,6^{*}}$ (D)
}

\begin{abstract}
Background: Accommodating a patient's treatment preference has been reported to promote greater responsiveness and better clinical outcomes. The effect of administration route preference (ARP) on the individual analgesic response has not been extensively examined to date. This study aimed to investigate whether ARPmatched treatment, i.e., individualized intramuscular (IM) or oral (PO) analgesic administration according to patient choice, would increase the analgesic effect.

Methods: In this prospective randomized study, we collected 38 patients with acute low back pain (aLBP) presenting at the emergency room of the Galilee Medical Center (Naharia, Israel) and asked them to report their ARP for analgesics. Regardless of their reported preference, they received either PO or IM diclofenac according to the treating physician's preference. Pain intensity was self-reported using the numeric pain score (NPS) before and during the first hour after drug administration.
\end{abstract}

Results: Both groups receiving PO or IM administration reported similar initial pain on admission, (NPS $8.63 \pm 1.5$ and $8.74 \pm 1.6$, respectively) and the same magnitude of pain reduction. However, patients who received the drug in their desired route (oral or injection) had a significantly greater reduction in pain levels $(4.05 \pm 2.8)$ as compared with patients who received the undesired route $(2.08 \pm 1.8), p<0.05$.

Conclusions: These findings support the hypothesis that individualized ARP-matched treatment in aLBP improves therapeutic outcomes, although further studies with larger cohorts are needed.

Keywords: Back pain, Placebo, Patient preference, Individualized medicine, Administration route preference

\section{Background}

The American Pain Society guideline \#11 on management of postoperative pain advocates avoiding painful administration of analgesic therapy [1], thus favoring oral administration over intramuscular injections. As some patients prefer injections and perceive them as being more beneficial than oral therapy [2], adhering to the guideline can

\footnotetext{
* Correspondence: nimrodr@gmc.gov.li; nim205@gmail.com

${ }^{4}$ Bar-llan University Medical School, Safad, Israel

${ }^{6}$ Dept. of Orthopedics B and Spine Surgery, Galilee Medical Center, Naharia, Israel

Full list of author information is available at the end of the article
}

come in contrast with the patient-centered trends of recent years and the attempt to individualize treatment $[3,4]$.

Fosnocht et al. [2] have established that most patients in the emergency department will have an administration route preference (ARP), $66 \%$ preferring oral medications (PO), 15\% intramuscular (IM), and 19\% intravenous (IV). Lindheim et al. [5] in their meta-analysis found a statistically significant effect of shared decision-making and treatment choice on treatment satisfaction, increased completion rates, and clinical outcome.

Greater satisfaction and improvement are assumed to operate through mechanisms attributed also to the

(c) The Author(s). 2020 Open Access This article is distributed under the terms of the Creative Commons Attribution 4.0 International License (http://creativecommons.org/licenses/by/4.0/), which permits unrestricted use, distribution, and reproduction in any medium, provided you give appropriate credit to the original author(s) and the source, provide a link to the Creative Commons license, and indicate if changes were made. The Creative Commons Public Domain Dedication waiver (http://creativecommons.org/publicdomain/zero/1.0/) applies to the data made available in this article, unless otherwise stated. 
placebo response, i.e., positive expectation and conditioning through past experience and beliefs [6]. It is currently accepted that the placebo response refers to the physiological processes experienced following the recognition of being treated, and not as a result of the inert procedure in itself [3]. Therefore, many medical treatments or medical rituals themselves may include a component of placebo response [7].

Prior experience, knowledge, and beliefs that shape positive expectations and conditioning are known to be key components in the placebo response [7] and are also involved in the formation of treatment preference [8], wherein preference can relate to both the type of medication and the mode of its delivery. While medication preference has been studied in this context in the past, the individualized ARP and analgesic ARP have been investigated far less $[2,9,10]$.

Our research hypothesis was that the ARP itself is a therapeutic ritual which can encompass key components of the placebo effect (i.e., expectation and conditioning). Thus, administering the same medication in the preferred ARP will increase the analgesic perception, essentially, "if you believe a certain ARP is better, it will be better for you." The purpose of this study was to investigate our hypothesis that an additive effect will be observed when an analgesic is received in a patient's ARP, as compared to the same therapeutic agent when received in an undesired method.

To test our hypothesis, patients with acute low back pain (aLBP) were studied, as it is a distinct entity with clear diagnostic criteria and commonly encountered in orthopedic practice. It is generally agreed that there is no known specific etiology and that virtually all cases will resolve with time, regardless of treatment $[11,12]$. Current guidelines profess aLBP needs no workup, and treatment is centered on pain relief and patient reassurance $[11,12]$.

Diclofenac is commonly used for the treatment of aLBP and other types of acute musculoskeletal pain. It is effective and can be administered both orally and intramuscularly to the gluteal muscles [13], making it useful for the purpose of this study. Intra-gluteal injections do have inherent complications such as sciatic nerve or vascular injury, injection site pain, myonecrosis, and infection [14], but they are less common in adults and are a trade-off to complications common to other administration routes $[13,15]$. This study did not investigate injections into spinal structures, at times utilized in chronic low back pain (CLBP) or radicular syndromes.

\section{Methods}

This was a randomized prospective case series performed at the emergency room of the Galilee Medical
Center (Naharia, Israel), during evening shifts (15:00 to 23:00) on April and May 2019.

Included were literate adults, 18 to 80 years old, who presented with acute low back pain (aLBP) defined as non-radicular pain, located in the lumbar spine, of a 1month duration or less, with no so-called "red flags" suggesting severe organic pathology [11].

Excluded were patients diagnosed differently or having a known sensitivity to diclofenac.

Patients, referred to our emergency department for acute low back pain, were enrolled by one of the authors (either SA or MG) and treated by the resident orthopedic surgeon. They were asked for their consent to participate in the study and report their ARP (oral administration vs. intramuscular injection) and their initial numeric pain score (NPS, scale of 0-10).

The NPS was chosen as it is a well-established validated measure for self-reported pain in low back pain [16]. The patient is requested to give a numeric value that corresponds to a 0-10 scale where "0" means "no pain at all" and "10" signifies "worst pain imaginable". A change of over 1.9 is considered to be the minimal clinically important difference [16].

All patients received a single dose of either intragluteal diclofenac $75 \mathrm{mg}$ (Abitren ${ }^{\odot}$ Teva $75 \mathrm{mg} / 3 \mathrm{ml}$, Israel) or $100 \mathrm{mg}$ diclofenac, orally (Betaren $100 \mathrm{SR}$, Dexel, Israel). The dosage differences were in accordance with the recommendations in the literature to adjust for differences in the absorption rate between the digestive system where only 65 to $75 \%$ of the active ingredient reaches the bloodstream [17] and the muscular tissue. Diclofenac appears to be completely absorbed when given as a suspension, capsule, or tablet. The administration of a diclofenac solution shows rapid absorption with Cmax being attained within 10 to $40 \mathrm{~min}$ [18].

As either IM or PO diclofenac are routinely used at our emergency department in the treatment of aLBP, allocation to receive one or the other (regardless of the initial analgesic ARP) was done according to the usual choice of the treating on-call resident physician, blinded to the ARP noted by the patient. Demographic and medical information was collected using a questionnaire, and NPS (0-10) were collected every 10 min during the first hour following the analgesic administration.

\section{Statistical analyses}

The statistical analysis was performed using IBM SPSS (SPSS Inc., Chicago, IL, USA, version 23).

The patients were divided according to their preference (i.e., IM or PO) and also according to the actual administration route. The term "matched" being patients where the actual administration route matched their preference whereas "non-matched" being patients in 
Table 1 Demographic data according to administration route

\begin{tabular}{|c|c|c|c|c|c|c|c|}
\hline & $\mathrm{PO}$ & & $\%$ of total sample & $\mathrm{IM}$ & & $\%$ of total sample & $P$ value \\
\hline & $N=13$ & $\%$ of group & 34.2 & $N=25$ & $\%$ of group & 65.8 & \\
\hline Age (mean \pm sd) & $42.8( \pm 15.7)$ & & & $43.48( \pm 15.25)$ & & & 0.288 \\
\hline Gender & & & & & & & 0.743 \\
\hline Female & 5 & $38.5 \%$ & 13.1 & 12 & $48 \%$ & 31.6 & \\
\hline Male & 8 & $61.5 \%$ & 21 & 13 & $52 \%$ & 34.2 & \\
\hline Place of birth & & & & & & & 0.108 \\
\hline Israel & 8 & $61.5 \%$ & 21.1 & 23 & $92 \%$ & 60.5 & \\
\hline Russia & 3 & $23.1 \%$ & 7.9 & 1 & $4 \%$ & 2.6 & \\
\hline North America & 1 & $7.7 \%$ & 2.6 & 1 & $4 \%$ & 2.6 & \\
\hline Africa & 1 & $7.7 \%$ & 2.6 & & & & \\
\hline Marital status & & & & & & & 0.571 \\
\hline Single & 2 & $15.4 \%$ & 5.3 & 6 & $24 \%$ & 15.8 & \\
\hline Married & 10 & $76.9 \%$ & 26.3 & 15 & $60 \%$ & 39.4 & \\
\hline Divorced & 1 & $7.7 \%$ & 2.6 & 4 & $16 \%$ & 10.5 & \\
\hline Widowed & 0 & & & 0 & & & \\
\hline Formal education & & & & & & & 0.176 \\
\hline None & 1 & $7.7 \%$ & 2.6 & 2 & $8 \%$ & 5.3 & \\
\hline Grade school & 1 & $7.7 \%$ & 2.6 & 3 & $12 \%$ & 7.9 & \\
\hline High school & 6 & $46.2 \%$ & 15.8 & 10 & $40 \%$ & 26.3 & \\
\hline Academic & 4 & $30.8 \%$ & 10.5 & 2 & $8 \%$ & 5.3 & \\
\hline Vocational & 1 & $7.7 \%$ & 2.6 & 8 & $32 \%$ & 21 & \\
\hline
\end{tabular}

which the actual administration route did not match their preference.

Dichotomic or discrete data were described by frequencies and percentages. Continuous variables were described by mean, standard deviation, and range. We compared the groups with parametric tests (chi-square test for the qualitative data and independent-sample $t$ test for the quantitative data) and also utilized nonparametric tests (Fisher's exact for the qualitative data if expectancy $<5$ and Wilcoxon rank-sum test if the sample size was small and the variable distribution violated significantly the normal distribution). Both tests, parametric and nonparametric, achieved similar results.

$P$ value less than 0.5 was considered a significant result. Two-tailed P values were noted.

\section{Results}

Included were 38 patients who met our inclusion criteria. Twenty were female and 18 male. The mean age was
43.45 years (median 41.5, std 14.32). Twenty-five patients received IM diclofenac and 13 PO. Both groups were identical in their demographic characteristics (Table 1).

The original intention was to collect 30 patients in each group to achieve a power of $81 \%$ (based on a 2 tailed independent-sample $t$ test, alpha $=5 \%$ ). Due of the difficulties in recruitment of patients, we had 16 patients in the non-matched group and 22 patients in the matched group and therefore achieved the power of $72 \%$ for our 1-tailed hypothesis (based on the required difference as mentioned above and also the final results of our research) (Table 2).

No differences were found in mean pain levels between the IM and PO groups, as both groups reported similar severe initial pain, (NPS $8.63 \pm 1.5$ and $8.74 \pm$ 1.6, respectively) as well as a similar magnitude of pain reduction (Fig. 1, Table 3 ).

To further stratify the results, 4 groups of preference were created (Table 2):

Table 2 Patient grouping according to ARP vs. actual administration method

\begin{tabular}{llll}
\hline & Administration route preference & $\mathrm{IM}(n=17)$ \\
\cline { 2 - 4 } & & $\mathrm{PO}(n=21)$ & $\mathrm{B}($ prefer IM, received PO, $n=4)$ \\
\hline Actual administration method & $\mathrm{PO}(n=13)$ & $\mathrm{A}($ prefer PO, received PO, $n=9)$ & $\mathrm{D}($ prefer IM, received IM, $n=13)$ \\
& $\mathrm{IM}(n=25)$ & $\mathrm{C}$ (prefer PO, received IM, $n=12)$ & \\
\hline
\end{tabular}




\section{Graph 1}

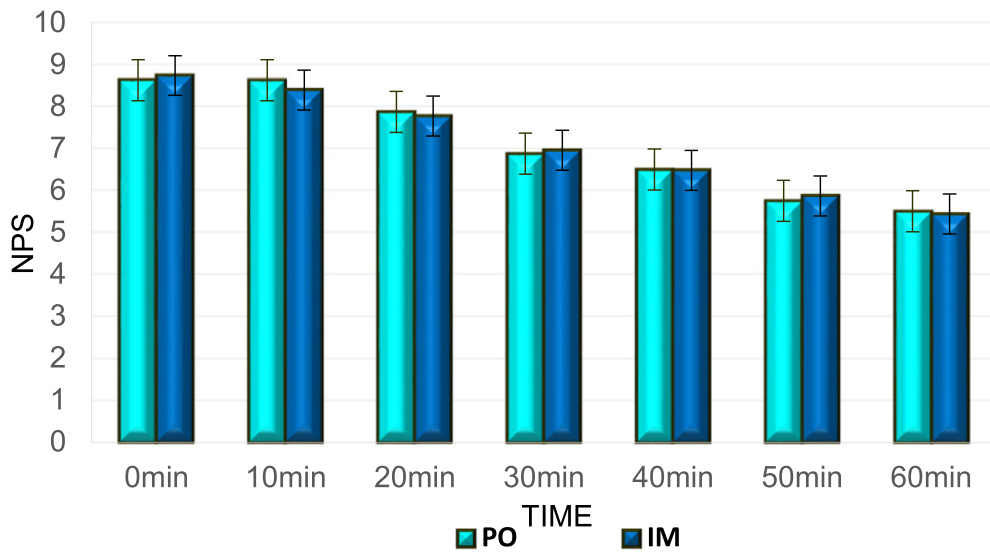

Fig. 1 Comparison between pain reduction in patients receiving PO and IM administration. Pain reduction did not show a significant difference between the two groups

A. Patients who preferred and received oral treatment $(n=9)$

B. Patients who preferred intramuscular injections and received oral treatment $(n=4)$

C. Patients who preferred oral treatment and received intramuscular injection $(n=12)$

D. Patients who preferred and received intramuscular injection $(n=13)$

Since group B was too small to perform statistical analysis, the four groups were re-divided into two groups:

1. Patients who were treated according to their ARP's-whether oral treatment or intramuscular injection (groups A and D in Table 2, $n=22$ )

2. Patients who received treatment that did not match their ARP's (groups B and C in Table 2, $n=16$ )
When the NPS reduction was examined according to this grouping, a consistent trend of a greater reduction in pain levels was observed in the group of patients treated according to their preference compared with those who received treatment that did not match their preference at $20 \mathrm{~min}$ post-administration. Statistical significance was reached at $50 \mathrm{~min}(P=0.019)$ and remained significant at $60 \mathrm{~min}(P=0.032)$ (Fig. 2, Table 4).

When divided into groups according to the administration method, the intramuscular group was larger than the oral group. To rule out the possibility that the effect was due to the injection itself, the group of patients who received IM medication according to their preference ( $n$ = 13) was compared to the group of patients who received oral medication according to their preference ( $n$ =9) (Fig. 3, Table 5) with no difference found between

Table 3 NPS reduction by administration route

\begin{tabular}{|c|c|c|c|c|c|c|c|}
\hline \multirow{2}{*}{$\begin{array}{l}\text { Time from } \\
\text { administration } \\
\text { (min) }\end{array}$} & \multirow{2}{*}{$\begin{array}{l}\text { Administration } \\
\text { route }\end{array}$} & \multirow[t]{2}{*}{$N$} & \multirow[t]{2}{*}{ Mean } & \multirow{2}{*}{$\begin{array}{l}\text { std } \\
\text { deviation }\end{array}$} & \multirow[t]{2}{*}{$P$} & \multicolumn{2}{|c|}{ 95\% confidence interval } \\
\hline & & & & & & Lower & Upper \\
\hline \multirow[t]{2}{*}{10} & $\mathrm{PO}$ & 13 & 8.08 & 1.706 & 0.755 & -1.511 & 1.104 \\
\hline & $\mathrm{IM}$ & 25 & 8.28 & 1.969 & & & \\
\hline \multirow[t]{2}{*}{20} & $\mathrm{PO}$ & 13 & 7.38 & 1.805 & 0.777 & -1.611 & 1.214 \\
\hline & IM & 24 & 7.58 & 2.125 & & & \\
\hline \multirow[t]{2}{*}{30} & $\mathrm{PO}$ & 13 & 6.62 & 2.399 & 0.826 & -1.872 & 1.503 \\
\hline & $\mathrm{IM}$ & 25 & 6.80 & 2.449 & & & \\
\hline \multirow[t]{2}{*}{40} & $\mathrm{PO}$ & 13 & 6.31 & 2.496 & 0.974 & -1.694 & 1.749 \\
\hline & IM & 25 & 6.28 & 2.475 & & & \\
\hline \multirow[t]{2}{*}{50} & $\mathrm{PO}$ & 13 & 5.62 & 2.567 & 0.908 & -1.918 & 1.709 \\
\hline & $\mathrm{IM}$ & 25 & 5.72 & 2.638 & & & \\
\hline \multirow[t]{2}{*}{60} & $\mathrm{PO}$ & 13 & 5.31 & 2.626 & 0.958 & -2.049 & 1.945 \\
\hline & IM & 25 & 5.36 & 2.998 & & & \\
\hline
\end{tabular}




\section{Graph 2}

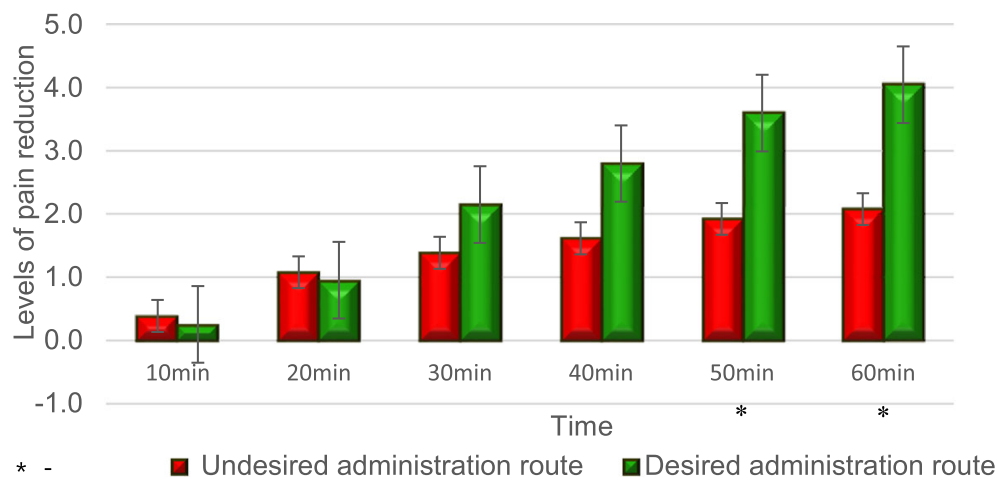

Fig. 2 Pain reduction in patients receiving the medication in the desired ARP versus the undesired ARP. The group receiving the medication in their desired ARP showed a significantly better reduction in self-reported pain levels, reaching statistical significance at 50 min post administration

these two groups, suggesting the injection itself was not the cause of this finding.

In addition to the observed statistical significance, it is also important to note that the difference between ARPmatched and non-matched groups closely matches or exceeds the $2 / 10$ minimal clinically important difference (MCID) in NPS [16]. The mean reduction in pain levels in the non-matched ARP group was 1.92 after $50 \mathrm{~min}$ and 2.08 after $60 \mathrm{~min}$. In the matched ARP group, the pain reduction was more pronounced, with a reduction of 3.6 and 4.05 points, respectively (at $50 \mathrm{~min}(p=$ $0.019)$ and at $60 \mathrm{~min}(p=0.032)$ ).

\section{Discussion}

It has long been established that patients have distinct preferences, including administration route preferences, and complying with individual preference can lead to greater patient satisfaction and treatment outcomes [2, $5,8-10,13,19,20]$. Our study aimed to find whether matching ARP for the same analgesic medication can result in better outcomes. We have found that ARP matching, $1 \mathrm{~h}$ post treatment, leads to an NPS reduction difference of more than two points (or twofold) better reduction when compared to non-ARP-matched treatment, although initial pain levels were similar.

Intramuscular administration may augment pain reduction due to activation of descending pain inhibition, as by the pain-inhibits-pain phenomena, in which the pain evoked by the needle activates descending pain pathways [21-23] suppressing pain. In addition, the "needle effect" [24, 25], in which the injection trauma itself is thought to instigate an analgesic response, may be part of the results found. To rule this out, patients who received their desired ARP (whether it be PO or IM) were compared, showing no difference.

As there was no difference in the analgesic effect between the administration method groups when given according to the ARP's, it can be assumed that it is not the

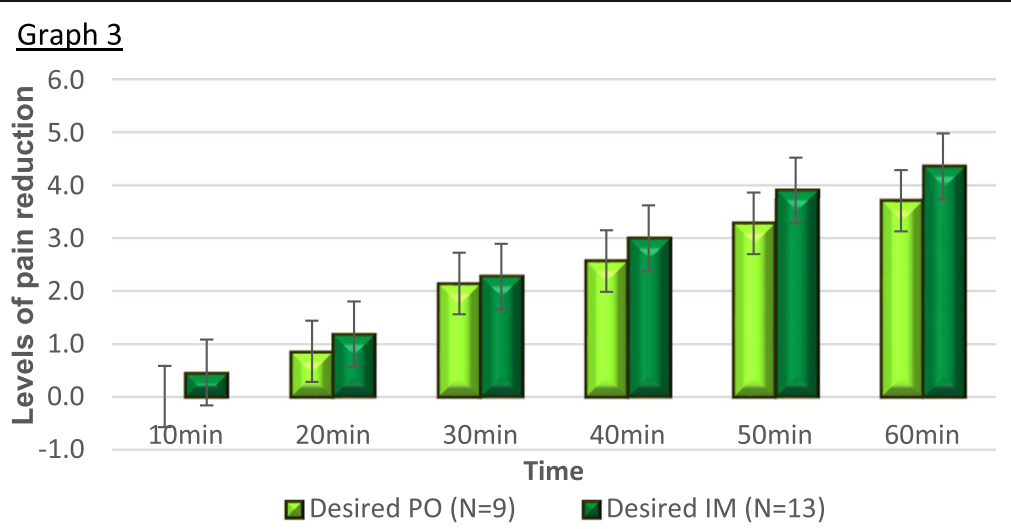

Fig. 3 Pain reduction in patients receiving the medication in their desired ARP. Both groups showed a similar reduction of self-reported pain levels regardless of administration route 
Table 4 NPS reduction by ARP matching

\begin{tabular}{|c|c|c|c|c|c|c|c|}
\hline \multirow{2}{*}{$\begin{array}{l}\text { Time from } \\
\text { administration } \\
\text { (min) }\end{array}$} & \multirow{2}{*}{$\begin{array}{l}\text { Matched } \\
\text { ARP }\end{array}$} & \multirow[t]{2}{*}{ N } & \multirow[t]{2}{*}{ Mean } & \multirow{2}{*}{$\begin{array}{l}\text { std } \\
\text { deviation }\end{array}$} & \multirow[t]{2}{*}{ P } & \multicolumn{2}{|c|}{ 95\% confidence interval } \\
\hline & & & & & & Lower & Upper \\
\hline \multirow[t]{2}{*}{10} & No & 16 & .3125 & .79320 & 0.710 & -0.37672 & 0.54718 \\
\hline & Yes & 22 & .2273 & .61193 & & & \\
\hline \multirow[t]{2}{*}{20} & No & 15 & .9333 & 1.09978 & 0.953 & -0.81030 & 0.85878 \\
\hline & Yes & 22 & .9091 & 1.30600 & & & \\
\hline \multirow[t]{2}{*}{30} & No & 16 & 1.3125 & 1.25000 & 0.182 & -1.82649 & 0.36058 \\
\hline & Yes & 22 & 2.0455 & 2.05814 & & & \\
\hline \multirow[t]{2}{*}{40} & No & 16 & 1.5000 & 1.41421 & 0.061 & -2.42238 & 0.05874 \\
\hline & Yes & 22 & 2.6818 & 2.12438 & & & \\
\hline \multirow[t]{2}{*}{50} & No & 16 & 1.8750 & 1.40831 & 0.019 & -2.88515 & -0.27395 \\
\hline & Yes & 22 & 3.4545 & 2.52091 & & & \\
\hline \multirow[t]{2}{*}{60} & No & 16 & 2.1250 & 1.66833 & 0.032 & -3.31843 & -0.15885 \\
\hline & Yes & 22 & 3.8636 & 2.76535 & & & \\
\hline
\end{tabular}

administration method per se which led to the significance of the findings, but rather the ARP matching.

In addition to the observed statistical significance, it is also important to note that the difference between ARPmatched and non-matched groups exceeded the 2/10 accepted MCID in NPS for back pain [16] or the $15 / 100$ for mixed acute pain in the emergency department [19].

Although shared decision-making has been well established as beneficial in patient compliance, satisfaction, and clinical outcomes [3, 6, 8, 9, 26, 27], we have not found in the literature previous studies focusing on the specific effect of ARP matching on pain reduction. Preference in general is associated with prior knowledge, at- titudes, belief, learning, and conditioning and therefore expresses an expectation of a positive effect of the preferred treatment. All of these have been associated with endogenous processes that promote recovery [28]. Furthermore, expectation learning and conditioning are known to be key components of the placebo phenomenon [29-31]. It is therefore possible that the analgesic improvement demonstrated in this study also involves a placebo response.

Our findings also support shared decision-making regarding treatment and emphasize the importance of considering other factors that shape the experience of pain other than the physiological aspect $[32,33]$.

Table 5 NPS reduction by administration route in patients that received their ARP

\begin{tabular}{|c|c|c|c|c|c|c|c|}
\hline \multirow{2}{*}{$\begin{array}{l}\text { Time from } \\
\text { administration } \\
\text { (min) }\end{array}$} & \multirow{2}{*}{$\begin{array}{l}\text { Desired } \\
\text { and } \\
\text { received } \\
\text { (matched) } \\
\text { ARP }\end{array}$} & \multirow[t]{2}{*}{$N$} & \multirow[t]{2}{*}{ Mean } & \multirow{2}{*}{$\begin{array}{l}\text { std } \\
\text { deviation }\end{array}$} & \multirow[t]{2}{*}{$P$} & \multicolumn{2}{|c|}{ 95\% confidence interval } \\
\hline & & & & & & Lower & Upper \\
\hline \multirow[t]{2}{*}{10} & $\mathrm{PO}$ & 10 & .0000 & .00000 & .114 & -0.94191 & 0.10858 \\
\hline & $\mathrm{IM}$ & 12 & .4167 & .79296 & & & \\
\hline \multirow[t]{2}{*}{20} & $\mathrm{PO}$ & 10 & 1.0000 & 1.15470 & .774 & -1.02607 & 1.35940 \\
\hline & $\mathrm{IM}$ & 12 & .8333 & 1.46680 & & & \\
\hline \multirow[t]{2}{*}{30} & $\mathrm{PO}$ & 10 & 2.1000 & 1.85293 & .913 & -1.78306 & 1.98306 \\
\hline & $\mathrm{IM}$ & 12 & 2.0000 & 2.29624 & & & \\
\hline \multirow[t]{2}{*}{40} & $\mathrm{PO}$ & 10 & 2.6000 & 2.11870 & .874 & -2.09300 & 1.79300 \\
\hline & $\mathrm{IM}$ & 12 & 2.7500 & 2.22077 & & & \\
\hline \multirow[t]{2}{*}{50} & $\mathrm{PO}$ & 10 & 3.2000 & 2.39444 & .676 & -2.76354 & 1.83021 \\
\hline & IM & 12 & 3.6667 & 2.70801 & & & \\
\hline \multirow[t]{2}{*}{60} & $\mathrm{PO}$ & 10 & 3.3000 & 2.40601 & .396 & -3.51790 & 1.45124 \\
\hline & IM & 12 & 4.3333 & 3.05505 & & & \\
\hline
\end{tabular}


Our study has several limitations; the most notable is the small sample size that limited the statistical comparisons which could be performed.

Since the treatment given in this study was mostly by orthopedics residents on call, another limitation is the variability of caregivers, the amount of time they had to interact with the patients, and their personal ability to convey compassion and trust-key elements in clinical practice success.

Due to these limitations, we cannot argue that the adjustment of the ARP to the treatment given, regardless of the type of treatment or method of administration, is solely responsible for the outcome. To establish this, further studies with larger samples are needed.

\section{Conclusions}

The findings of our current study support previously published data that treatment based on patient preference improves therapeutic and analgesic outcomes [20, 26,27 and adds the administration route preference as an additional consideration for the practitioner when prescribing analgesic treatment.

\section{Abbreviations}

aLBP: Acute low back pain; ARP: Administration route preference;

IM: Intramuscular; NPS: Numeric pain score; PO: Per os

\section{Acknowledgements}

We wish to thank Ms. Orly Yakir for performing the statistical analysis and her helpful suggestions.

\section{Authors' contributions \\ AS co-conceived the research hypothesis and study design, provided back- ground research, submitted IRB request, overviewed data collection, and wrote the draft manuscript. MG co-conceived the research hypothesis and study design, provided background research, and edited the draft manu- script. GM assisted in study planning, collected the data in the emergency room, and assisted in statistical analysis and draft manuscript preparation. BR assisted in study planning and data collection. NR co-conceived the research hypothesis and study design, provided background research, overviewed statistical analysis, edited the draft, and wrote the final manuscript. All au- thors read and approved the final manuscript.}

\section{Funding}

No external funding was received in connection with this research.

\section{Availability of data and materials}

All data is provided in the manuscript and tables. There are no supplementary data or material.

\section{Ethics approval and consent to participate}

This study was approved by the Galilee Medical Center's institutional review board, ref. \# 0032-19-NHR dated March 14, 2019.

As treatment did not differ from normal practice and patients were only asked to fill in an anonymous questionnaire, informed consent to participate in the study was not required by the IRB.

\section{Consent for publication}

No individual patient data, images, videos, or voice recordings were collected. Consent for publication is therefore not required.

\section{Competing interests}

The authors declare that they have no competing interests.

\section{Author details}

${ }^{1}$ Spine Surgery Unit, Galilee Medical Center, Naharia, Israel. ²Dept. of Nursing, Faculty of Social Welfare and Health Sciences, University of Haifa, Haifa, Israel. ${ }^{3}$ Dept. of Orthopedics B, Galilee Medical Center, Naharia, Israel. ${ }^{4}$ Bar-Ilan University Medical School, Safad, Israel. ${ }^{5}$ Dept. of Emergency Medicine, Galilee Medical Center, Naharia, Israel. ${ }^{6}$ Dept. of Orthopedics B and Spine Surgery, Galilee Medical Center, Naharia, Israel.

Received: 9 October 2019 Accepted: 13 February 2020

Published online: 27 February 2020

\section{References}

1. Chou R, Gordon DB, de Leon-Casasola OA, Rosenberg JM, Bickler S, Brennan $T$, et al. Management of postoperative pain: a clinical practice guideline From the American Pain Society, the American Society of Regional Anesthesia and Pain Medicine, and the American Society of Anesthesiologists' Committee on Regional Anesthesia, Executive Committee, and Administrative Council. J Pain. 2016;17(2):131-57.

2. Fosnocht DE, Hollifield MB, Swanson ER. Patient preference for route of pain medication delivery. J Emerg Med. 2004;26(1):7-11.

3. Ring D, Bozic KJ. Value-based Healthcare: The value of considering patient preferences and circumstances in orthopaedic surgery. Clin Orthop Relat Res. 2016:474(3):633-5

4. Constand MK, MacDermid JC, Dal Bello-Haas V, Law M. Scoping review of patient-centered care approaches in healthcare. BMC Health Serv Res. 2014; 14:271.

5. Lindhiem O, Bennett CB, Trentacosta CJ, McLear C. Client preferences affect treatment satisfaction, completion, and clinical outcome: a meta-analysis. Clin Psychol Rev. 2014;34(6):506-17.

6. Preference Collaborative Review Group. Patients'preferences within randomised trials: systematic review and patient level meta-analysis. BMJ. 2008;337:a1864.

7. Palese A, Cadorin L, Testa M, Geri T, Colloca L, Rossettini G. Contextual factors triggering placebo and nocebo effects in nursing practice: findings from a national cross-sectional study. J Clin Nurs. 2019;28(9-10):1966-78.

8. Street RL Jr, Elwyn G, Epstein RM. Patient preferences and healthcare outcomes: an ecological perspective. Expert Rev Pharmacoecon Outcomes Res. 2012;12(2):167-80

9. Mitsikostas DD, Belesioti I, Arvaniti C, Mitropoulou E, Deligianni C, Kasioti E, et al. Patients' preferences for headache acute and preventive treatment. J Headache Pain. 2017;18(1):102.

10. Wong A, Kraus PS, Lau BD, Streiff MB, Haut ER, Hobson DB, et al. Patient preferences regarding pharmacologic venous thromboembolism prophylaxis. J Hosp Med. 2015;10(2):108-11.

11. Oliveira CB, Maher CG, Pinto RZ, Traeger AC, Lin CC, Chenot JF, et al. Clinical practice guidelines for the management of non-specific low back pain in primary care: an updated overview. Eur Spine J. 2018;27(11):2791-803.

12. Qaseem A, Wilt TJ, McLean RM, Forciea MA. Noninvasive rreatments for acute, subacute, and chronic low back pain: a clinical practice guideline from the American College of Physicians. Ann Intern Med. 2017;166(7):514-30.

13. Qureshi I, Pathan SA, Qureshi RS, Thomas SH. Intramuscular versus oral diclofenac for acute pain in adults with acute musculoskeletal injuries presenting to the ED setting: a prospective, double-blind, double-dummy, randomised controlled trial. Emerg Med J. 2019;36(7):401-6.

14. Mishra $P$, Stringer MD. Sciatic nerve injury from intramuscular injection: a persistent and global problem. Int J Clin Pract. 2010;64(11):1573-9.

15. Tramer MR, Williams JE, Carroll D, Wiffen PJ, Moore RA, McQuay HJ. Comparing analgesic efficacy of non-steroidal anti-inflammatory drugs given by different routes in acute and chronic pain: a qualitative systematic review. Acta Anaesthesiol Scand. 1998;42(1):71-9.

16. Childs JD, Piva SR, Fritz JM. Responsiveness of the numeric pain rating scale in patients with low back pain. Spine (Phila Pa 1976). 2005;30(11):1331-4.

17. Todd PA, Sorkin EM. Diclofenac sodium. A reappraisal of its pharmacodynamic and pharmacokinetic properties, and therapeutic efficacy. Drugs. 1988;35(3):244-85.

18. Davies NM, Anderson KE. Clinical pharmacokinetics of diclofenac. Therapeutic insights and pitfalls. Clin Pharmacokinet. 1997;33(3):184-213.

19. Olsen MF, Bjerre E, Hansen MD, Hilden J, Landler NE, Tendal B, et al. Pain relief that matters to patients: systematic review of empirical studies assessing the minimum clinically important difference in acute pain. BMC Med. 2017;15(1):35. 
20. Ringdal M, Chaboyer W, Ulin K, Bucknall T, Oxelmark L. Patient preferences for participation in patient care and safety activities in hospitals. BMC Nurs. 2017;16:69.

21. Granot M, Weissman-Fogel I, Crispel Y, Pud D, Granovsky Y, Sprecher E, et al. Determinants of endogenous analgesia magnitude in a diffuse noxious inhibitory control (DNIC) paradigm: do conditioning stimulus painfulness, gender and personality variables matter? Pain. 2008;136(1-2):142-9.

22. Le Bars $\mathrm{D}$, Dickenson AH, Besson JM. Diffuse noxious inhibitory controls (DNIC). I. Effects on dorsal horn convergent neurones in the rat. Pain. 1979; 6(3):283-304.

23. Yarnitsky D. Conditioned pain modulation (the diffuse noxious inhibitory control-like effect): its relevance for acute and chronic pain states. Curr Opin Anaesthesiol. 2010;23(5):611-5.

24. Dommerholt J, Grieve R, Layton M, Hooks T. An evidence-informed review of the current myofascial pain literature--January 2015. J Bodyw Mov Ther. 2015;19(1):126-37.

25. Gattie E, Cleland JA, Snodgrass S. The effectiveness of trigger point dry needling for musculoskeletal conditions by physical therapists: a systematic review and meta-analysis. J Orthop Sports Phys Ther. 2017;47(3):133-49.

26. Conn VS, Ruppar TM, Enriquez M, Cooper PS. Patient-centered outcomes of medication adherence interventions: systematic review and meta-analysis. Value Health. 2016;19(2):277-85.

27. Coulter A, Entwistle VA, Eccles A, Ryan S, Shepperd S, Perera R. Personalised care planning for adults with chronic or long-term health conditions. Cochrane Database Syst Rev. 2015;3:Cd010523.

28. Thompson KA, Bulls HW, Sibille KT, Bartley EJ, Glover TL, Terry EL, et al. Optimism and psychological resilience are beneficially associated with measures of clinical and experimental pain in adults eith or at risk for knee osteoarthritis. Clin J Pain. 2018;34(12):1164-72.

29. Colloca L, Grillon C. Understanding placebo and nocebo responses for pain management. Curr Pain Headache Rep. 2014;18(6):419.

30. Munnangi S, Angus LD. Placebo Effect. StatPearls. Treasure Island (FL): StatPearls Publishing StatPearls Publishing LLC.; 2019

31. Price DD, Finniss DG, Benedetti F. A comprehensive review of the placebo effect: recent advances and current thought. Annu Rev Psychol. 2008;59: $565-90$

32. Carlino E, Benedetti F. Different contexts, different pains, different experiences. Neuroscience. 2016;338:19-26.

33. Carlino E, Frisaldi E, Benedetti F. Pain and the context. Nat Rev Rheumatol. 2014;10(6):348-55.

\section{Publisher's Note}

Springer Nature remains neutral with regard to jurisdictional claims in published maps and institutional affiliations.

Ready to submit your research? Choose BMC and benefit from:

- fast, convenient online submission

- thorough peer review by experienced researchers in your field

- rapid publication on acceptance

- support for research data, including large and complex data types

- gold Open Access which fosters wider collaboration and increased citations

- maximum visibility for your research: over $100 \mathrm{M}$ website views per year

At BMC, research is always in progress.

Learn more biomedcentral.com/submissions 